\title{
Mars Observer Mission
}

\author{
A. L. AlbeE \\ California Institute of Technology, Pasadena
}

R. E. ARVIDSON

McDonnell Center for Space Sciences, Washington University, Saint Louis, Missouri

\author{
F. D. Palluconi
}

Jet Propulsion Laboratory, Pasadena, California

\begin{abstract}
The Mars Observer mission will extend the exploration and characterization of Mars by providing new and systematic measurements of the atmosphere, surface, and interior of the planet. These measurements will be made from a low-altitude polar orbiter over a period of 1 Martian year, permitting repetitive observations of the surface and of the seasonal variations of the atmosphere. The mission will be conducted in a manner that will provide new and valuable scientific data using a distributed data system that minimizes operational complexity and cost.
\end{abstract}

\section{INTRODUCTION}

The Mars Observer spacecraft will be placed into orbit about Mars in August 1993 (Figure 1). After 4 months of trim maneuvers to come into a circular orbit, the spacecraft will begin mapping the atmosphere, surface, and interior for at least 1 Martian year. The primary geoscience objectives for Mars Observer include the global definition of the topography and gravitational fields, global determination of the elemental and mineralogical character of surface materials, and determination of the nature of the magnetic field around Mars. The primary climatology objectives are the determination of the time and space distribution, abundances, sources, and sinks of volatile material and dust over a seasonal cycle, as well as the delineation of atmospheric structure and dynamics. Mars Observer will provide a basic global understanding of Mars as it exists today and will provide a framework for understanding its past. It will also establish a base of knowledge for future Mars missions, including network science, returned samples, and an eventual piloted landing.

This paper is an overview of the Mars Observer mission. Emphasis is placed on summarizing key science objectives, and providing high-level descriptions of the spacecraft, mapping orbit, and mission operations. Further, we provide an overview of science analysis and archiving functions. Note that each Mars Observer instrument is described in detail in a suite of papers included in this issue and authored by members of the respective instrument teams. More detailed information on the mission elements and the spacecraft can be obtained from a group of technical papers [Allbee and Palluconi, 1991; Beerer and Roncoli, 1991; Blume et al., 1991; Erickson and McKinley, 1991; Esposito et al., 1991; Halsell and Bollman, 1991; Komro and Hujber, 1991; Malin et al., 1991; McCleese et al., 1986; McKinley, 1991; Palocz, 1991; Potts, 1991].

Copyright 1992 by the American Geophysical Union.

Paper number $92 \mathrm{JE} 00342$.

0148-0227/92/92JE-00342\$05.00

\section{Mission Overview}

Mars Observer will be launched on a Titan III rocket from Cape Kennedy, Florida, in September 1992. Figure 1 provides an overview of the mission. After an 11-month transit, the spacecraft will be injected into an elliptical orbit about Mars with a periapsis near the north pole. The orbit will then be adjusted through a series of maneuvers to a near-circular, near-polar, Sun-synchronous orbit with an average altitude of $400 \mathrm{~km}$ and $0200 / 1400 \mathrm{LT}$ equatorial crossing times.

The mapping orbit has a 118-min period with a 7-sol near-repeat ground track (a sol is a Martian day, about 5\% longer than an Earth day). Each 7-sol cycle will be systematically offset from the next, and as a result, the planet will be repeatedly mapped in 26-sol cycles, with a 58.6-km nominal path separation. Orbit trim adjustments will make it possible to obtain uniform coverage during the course of the mission, with an ultimate spacing of ground tracks at the equator of $3.1 \mathrm{~km}$. The mapping orbit meets the planetary protection requirement that the unsterilized spacecraft not impact the planet before the year 2039 (NASA Management Instruction, NHB-8020).

The spacecraft provides a three-axis stabilized, nadiroriented platform for continuous observations of Mars. During at least 1 Martian year (687 Earth days) of observations, the instruments will acquire data in a systematic program of global mapping. Table 1 provides a summary of instruments and their capabilities. The normal observation sequence will be to record continuously for 24 hours and to then play the data back in one 10-hour link to a 34-m NASA Deep Space Network tracking station. In addition, approximately every 3 days, a real-time link will be used to transmit data at a relatively high rate.

With this mission overview, we now discuss the major science objectives that guided the mission design and instrument selections.

\section{SCIEnCe Objectives}

The primary Mars Observer science objectives are to (1) determine the global elemental and mineralogical character- 


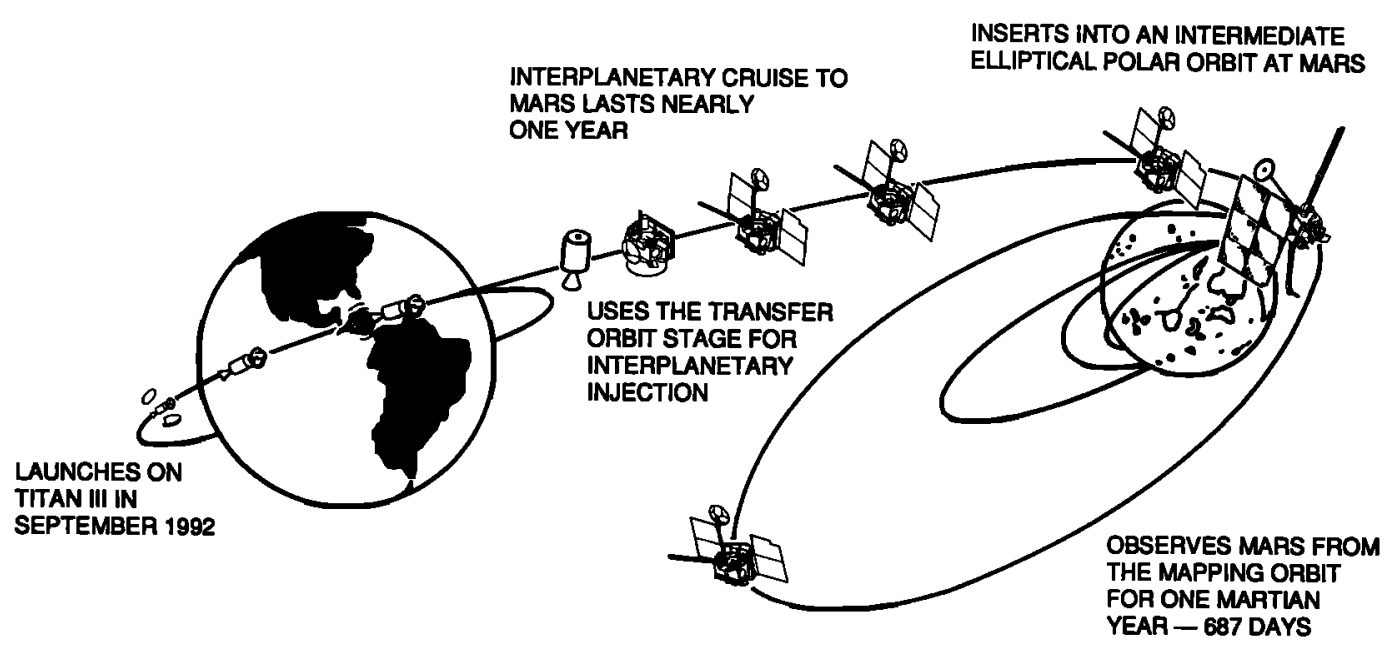

Fig. 1. Mission outline for the 3.4-year duration of the Mars Observer mission.

istics of surface materials; (2) define the global topography and gravity fields; (3) establish the nature of the magnetic field; (4) determine the time and space distribution, abundance, sources, and sinks of volatile material and dust over a seasonal cycle; and (5) explore the structure and dynamics of the atmosphere. These objectives and the mission itself are derived from the recommendations of the Solar System Exploration Committee (SEEC) [1983, pp. 95-99].

All the objectives require mapping that results in derived data sets that have spatial and temporal dimensions. For the geoscience objectives the intent is to generate a suite of products that depict surface and subsurface characteristics as a function of latitude, longitude, elevation, and season. For many climatology objectives the data sets will be organized by latitude, longitude, altitude, and season. As a result, this mission will obtain a systematic global characterization of Mars, as it exists today. This characterization will also help us to understand the geologic and climatologic history of Mars and the evolution of its interior and surface and will provide bases for comparison with Venus and Earth.

\section{Geoscience}

The first three science objectives listed above involve measurement of geological, geochemical, and geophysical quantities. Mars is a single-plate planet, with a surface area that is slightly larger than the combined area of all the plates that make up Earth's continents. Mapping of the $144 \times 10^{6}$ $\mathrm{km}^{2}$ of Martian surface will occur over the full Martian year planned for the mission. The Martian crust includes highaltitude, heavily cratered uplands in the southern hemisphere and lower, sparsely cratered plains in the northern hemisphere (Figure 2). The Tharsis Plateau is a 4- to $10-\mathrm{km}$ high, $4000-\mathrm{km}$-wide zone of relatively young volcanic flows and large volcanic constructs that straddles the Martian

TABLE 1. Characteristics of the Mars Observer Instruments

\begin{tabular}{|c|c|c|c|c|}
\hline Instrument & Measurements & $\begin{array}{l}\text { Mass, } \\
\mathrm{kg}\end{array}$ & $\begin{array}{l}\text { Average* } \\
\text { Peak Power, } \\
\text { W }\end{array}$ & $\begin{array}{l}\text { Data Rate } \\
\text { bits/s }\end{array}$ \\
\hline $\begin{array}{l}\text { Gamma ray spectrometer } \\
\text { (GRS) }\end{array}$ & $\begin{array}{l}\text { primary/secondary gamma rays, bursts at } 0.2-10 \\
\mathrm{MeV} \text { and neutrons to } 10 \mathrm{keV}\end{array}$ & 23.2 & $14.0 / 34.9$ & 665 \\
\hline $\begin{array}{l}\text { Mars Observer camera } \\
\text { (MOC) }\end{array}$ & $\begin{array}{l}\text { Imaging-narrow and wide fields at } f 10,3.5 \mathrm{~m} \text { for } 0.5- \\
0.9 \mu \mathrm{m} \text {, at } f 6.5,11.3 \mathrm{~mm} \text { for blue and red }(0.4 \\
0.45 \text { and } 0.58-0.63 \mathrm{um})\end{array}$ & 21.4 & $7.5 / 25.7$ & $\begin{array}{r}700 / 2856 / 9120 \\
(29260) \mathrm{RT} \dagger\end{array}$ \\
\hline $\begin{array}{l}\text { Thermal emission } \\
\text { spectrometer (TES) }\end{array}$ & $\begin{array}{l}\text { interferometer at } 6-\text { to } 50 \text {-um spectral range and } \\
\text { broadbands at } 0.3-3.0 \text { and } 4.5-100 \mathrm{um}\end{array}$ & 14.1 & $13.2 / 18.3$ & $\begin{array}{l}\text { 688/1664/ } \\
(4992) \mathrm{RT} \dagger\end{array}$ \\
\hline $\begin{array}{l}\text { Mars Mars Observer laser } \\
\text { altimeter (MOLA) }\end{array}$ & $\begin{array}{l}\text { topography-74-cm focal length telescope sends and } \\
\text { receives } 1.06-\text { um laser pulse; } 150 \text {-m footprint at } \\
2-\mathrm{m} \text { timing accuracy }\end{array}$ & 25.9 & $23.1 / 30.2$ & 618 \\
\hline $\begin{array}{l}\text { Ultrastable oscillator } \\
\text { (USO/RS) }\end{array}$ & $\begin{array}{l}\text { oscillator provides precision frequency reference for } \\
\text { radio science measurements during occultations }\end{array}$ & 1.3 & $2.2 / 4.2$ & N/A \\
\hline $\begin{array}{l}\text { Magnetometer/electron } \\
\text { reflectometer (MAG/ER) }\end{array}$ & $\begin{array}{l}\text { magnetic fields in the range from } 16 \text { to } 65536 \mathrm{nT} \text {; } \\
\text { electrons in the range from } 1 \text { to } 10 \mathrm{keV}\end{array}$ & 5.4 & $4.6 / 4.6$ & $324 / 648 / 1296$ \\
\hline $\begin{array}{l}\text { Pressure modulator IR } \\
\text { radiometer (PMIRR) }\end{array}$ & $\begin{array}{l}\text { six IR channels between } 7.0 \text { and } 46.5 \text { um with } \\
\text { pressure-modulated } \mathrm{CO}_{2} \text { and } \mathrm{H}_{2} \mathrm{O} \text { channels; } \\
\text { albedo at } 0.3-3.0 \mathrm{um}\end{array}$ & 40.9 & $34.1 / 34.7$ & 156 \\
\hline $\begin{array}{l}\text { Mars Balloon Relay } \\
\text { Experiment (MBR) }\end{array}$ & $\begin{array}{l}\text { signal relay receiver; interrogating at } 437 \mathrm{MHz} \text {; } \\
\text { receiving at } 401 \text { and } 406 \mathrm{MHz}\end{array}$ & 7.7 & $9.0 / 9.05$ & N/A \\
\hline
\end{tabular}

*Average is orbital average.

$\dagger R T$ is real-time rate. 


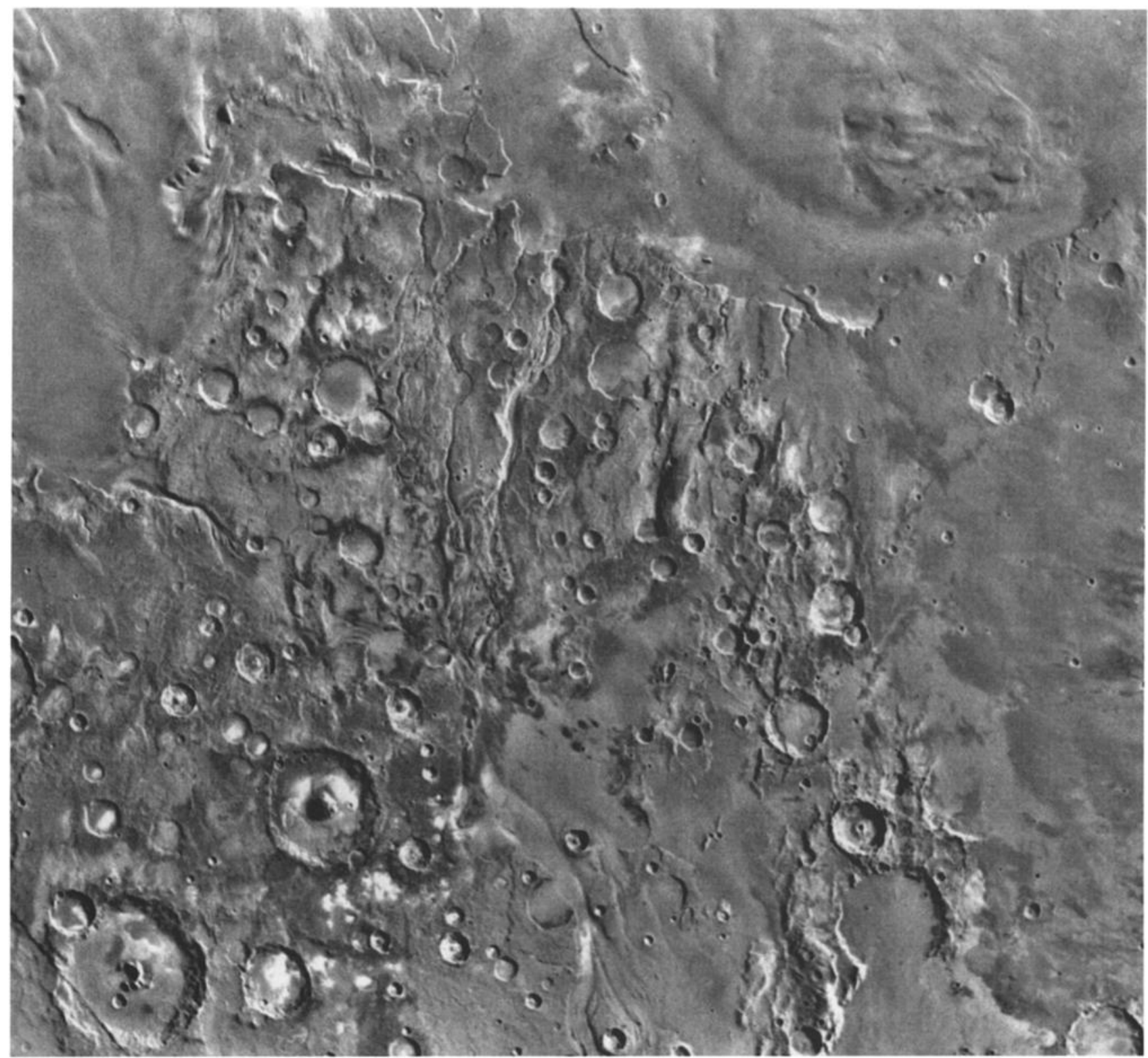

Fig. 2. Viking image mosaic of the contact between the cratered uplands and the northern plains centered on the Mangala Vallis. Mangala cuts through heavily cratered terrain and ends at the escarpment between the cratered upland and the plains. The smooth rolling plains to the northwest may be ignimbrite deposits. This is a mosaicked digital image model (MDIM) at approximately $6^{\circ}$ south latitude; $150^{\circ}$ west longitude. Frame width is about $1000 \mathrm{~km}$.

equator. Annual and permanent ice and associated layered deposits occur near each pole. Further, bedrock has been modified by crustal and surface processes to produce canyons and channels, chaotic, fretted, and hummocky terrains, and the surface is covered with a thin veneer of aeolian and locally derived soils.

Mars Observer data will be used to understand the distribution of chemical elements and minerals on the Martian surface in relation to the age, origin, nature, and weathering of the surface rocks. Simultaneous global mapping of the gravitational field, the surface topography, and the magnetic field will improve our understanding of both the surface and the interior of Mars. Combining these distinctly different measurements in a single mission exploits their inherent synergism and allows us to realistically address such global problems as Mars' bulk composition, the degree of differentiation of the planet, the chemical and mineralogical composition of the crust and mantle, and the nature and cause of the planet-wide dichotomy of uplands and plains.

The K/U ratio for Mars will be determined by the gamma ray spectrometer (GRS) and will provide an important constraint on bulk composition. Uranium provides an index for those elements that tend to condense from the solar nebula at high temperatures; potassium is an index for elements with lower condensation temperatures; yet both behave similarly in magmatic processes. Thus the $\mathrm{K} / \mathrm{U}$ value, coupled with other elemental ratios, provides a means of reconstructing the bulk composition of the planet. The content of these two elements in the crustal material also gives an indication of the degree of differentiation of the planet, 


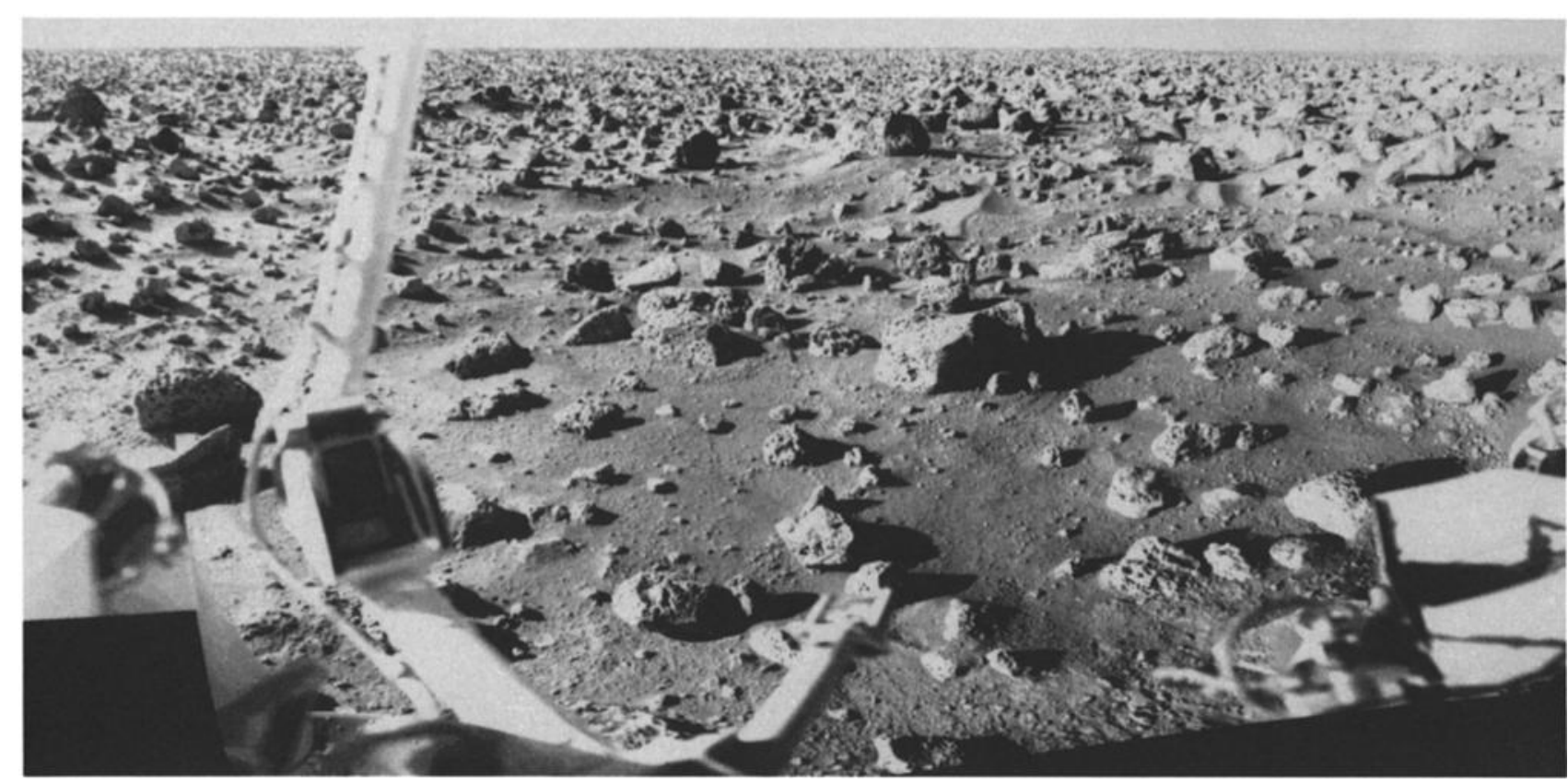

Fig. 3. Viking Lander image of soil and bedrock at the Lander 2 site. Panorama is generated from high-resolution $\left(0.04^{\circ}\right.$ angular resolution) data.

estimates of the amount of volatiles, including water, that have outgassed from the planet, and places constraints on the thermal evolution models.

A major question to be addressed by Mars Observer is the nature and cause of the planet-wide dichotomy into old cratered upland and sparsely cratered plains. Mars Observer will determine chemical and mineralogical differences between the two regions, how the crust and lithosphere differ beneath the two regions, and what is the nature of the boundary. These estimates will lead to a much better understanding of the nature of the dichotomy, what caused it, and when it occurred.

The volcanoes of Mars are well known, but we have little information on the chemistry and mineralogy of the lavas. This information would be of use to infer the composition of the mantle, the depth of origin of the magma, and whether magmas have undergone differentiation during passage from the source region to the surface. Mars Observer will also provide the data to tell if there are regional differences in composition that might result from differences in source rock or depth of origin of the magmas.

Mapping of the gravity and topographic fields will lead to better understanding of volcanic processes and the thermal evolution of the interior of Mars. Lithospheric thickness will be determined from the deformation of the crust by large volcanoes, as reflected in the topographic and gravity field data. Thermal conditions in the interior will be modeled based on the degree and depth of isostatic compensation of features such as craters, canyons, and volcanoes. Increase in the depth of compensation with the age of features would suggest that the lithosphere has thickened with time. Magnetic measurements will indicate whether conditions in the core today can sustain a planetary dynamo; local remnant magnetism may establish whether and when such conditions existed in the past.

Much of the Martian surface is covered with soils that are a combination of local and aeolian materials, including highly altered components (Figure 3 ). Tentative identifications have been made of specific absorption bands seen in telescopic observations, but we actually know very little about the chemistry and mineralogy of the surface. Mars Observer will provide basic characterization of these materials. We particularly want to understand the role of water, its form (adsorbed, ice, in minerals, etc.), and whether water-containing minerals are forming currently or are "fossil" from past climates. We may then infer how water is cycled during the current seasonal and obliquity cycles and whether significantly different climates in the past are required to explain the formation of the soil materials. Understanding the abundance of volatile-containing materials will lead to improved estimates of the amount of water and other volatiles outgassed from the planet and provide clues as to when the outgassed volatiles were removed from the atmosphere by escape or becoming fixed in the regolith.

Mars Observer also provides an opportunity for mapping the planet-wide distribution of ice in near-surface material. Ice is believed to be a major component in the polar-layered terrain (Figure 4), detectable by Mars Observer from both compositional and gravity information. Ice may also be present near the surface at high latitudes, its limit varying with the season. Detection of ice will depend upon its being close enough to the surface such that seasonal changes can be discerned. Detection of liquid water is not expected, but aberrant conditions might allow seepage to the surface. Such a discovery would lead to significant reassessment of how water is circulated about Mars.

Finally, more precise determination of topography and gravity will lead to a more complete understanding of almost every geologic process that has affected the surface. Our current understanding is based largely on surface morphology and is hindered by the lack of quantitative information against which different ideas can be tested. Better informa- 


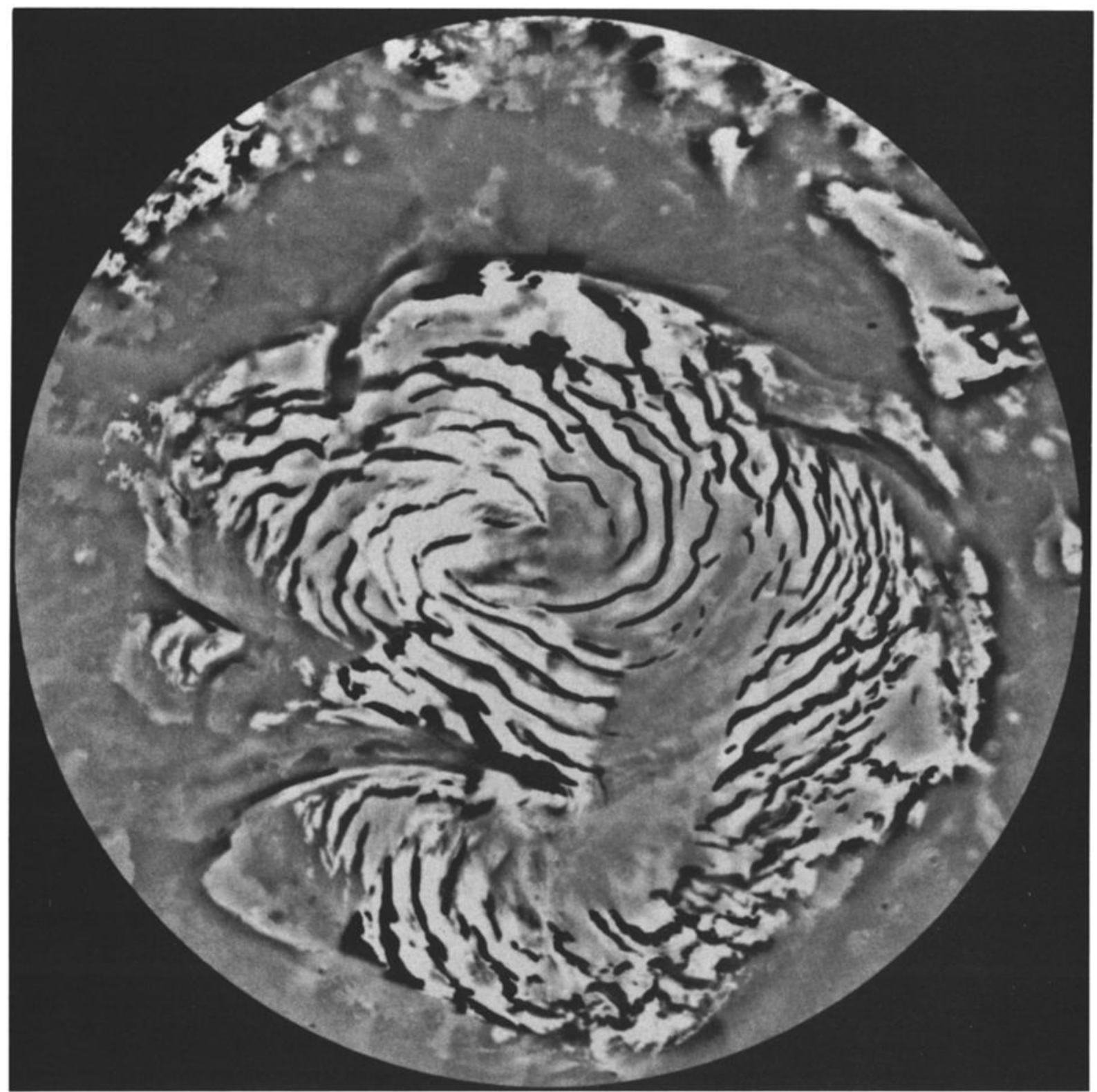

Fig. 4. Viking Orbiter image mosaic centered on the north pole and showing the residual north polar cap, layered deposits, and the dark circumpolar area of sand dunes. This is a Mars digital image mosaic (MDIM) with approximately $1500-\mathrm{km}$ frame width.

tion on slopes will lead to a better understanding of fluvial erosion and emplacement of lavas. Comparison of presentday slopes with original slopes as inferred from the gradients of lava flows or channels will provide information on deformation rates. Better information on gravity patterns of craters and on crater depths, rim heights, and ejecta thickness will lead to a more complete understanding of cratering.

In summary, acquisition of chemical, mineralogical, gravitational, and elevation data by Mars Observer will improve our understanding of almost every aspect of Martian geology. However, the main impact will be an improved understanding of global problems rather than local geologic processes, although regional studies will be utilized to address global-scale problems. Improved understanding of the planet's bulk composition, the composition of the crust and mantle, the thickness of the lithosphere, the thermal state of the interior, and the planet's outgassing history will inevita- bly follow from Mars Observer. This will be the mission's main geoscience legacy.

\section{Climate}

The fourth and fifth Mars Observer science objectives address volatile (carbon dioxide and water) and dust cycles and the Martian atmosphere. The emphasis will be on seasonal variations; hence the use of the term climatology. An understanding of the current climate of Mars will permit us to better assess how currently active processes (weathering, erosion, atmospheric transport, and dust deposition) are modifying the surface. If we are able to understand the current climate, we may more confidently project this knowledge back in time to periods when the Martian orbit, axial characteristics, and atmospheric pressure were different. In principle, determination of the daily as well as the 


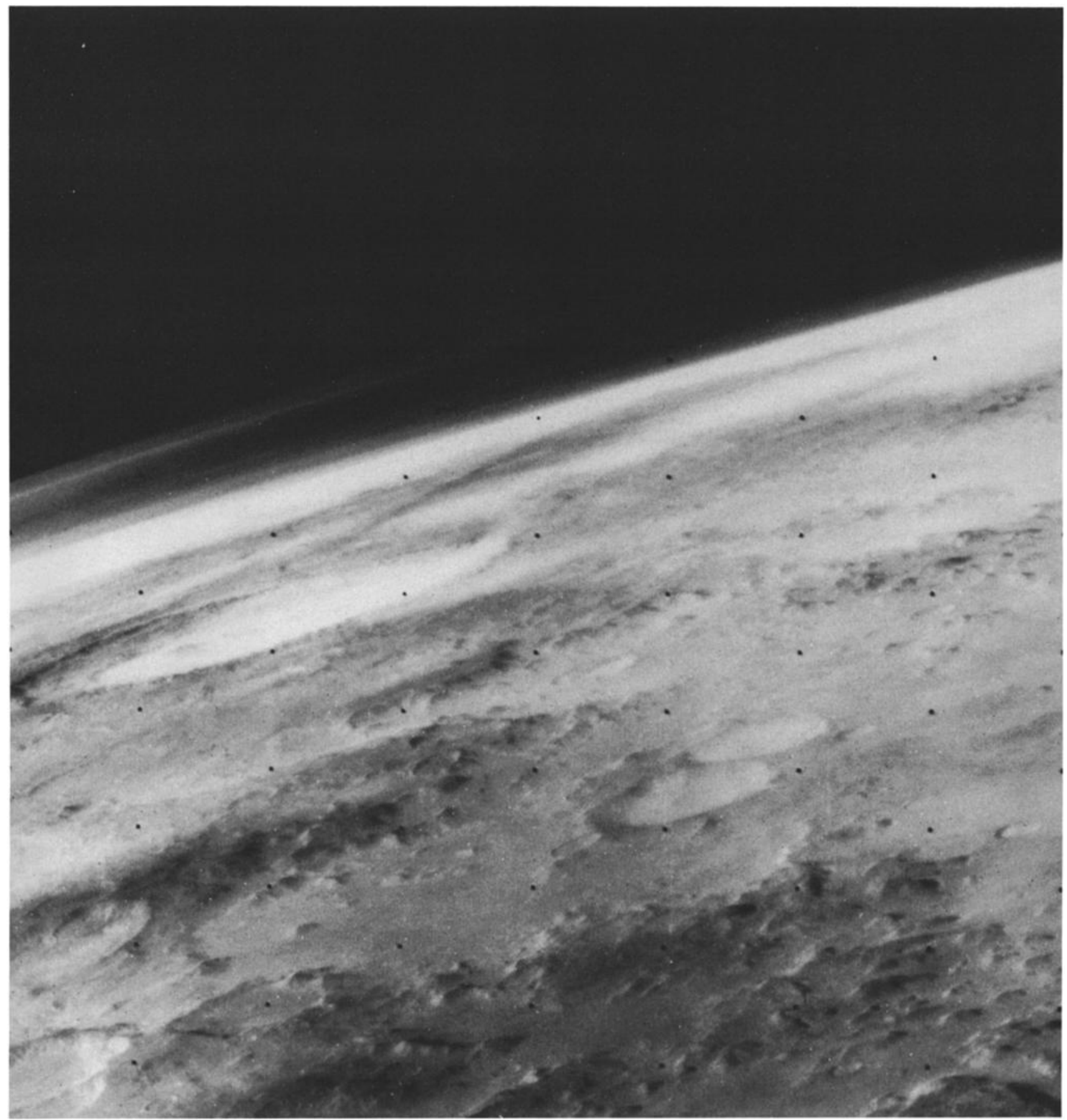

Fig. 5. The southern hemisphere surface and atmosphere in early winter from the Viking A Orbiter, $11,000 \mathrm{~km}$ from the surface. Limb clouds and hazes are common up to $40 \mathrm{~km}$. The pressure modulator IR radiometer (PMIRR) will view the trailing limb and both the morning and evening limbs. The spread in local time available at the equator for PMIRR is about $13 / 4$ hours.

seasonal behavior of the global atmosphere would be ideal. However, providing complete daily sampling is difficult from a single orbiting spacecraft and is not possible from the Sun-synchronous mapping orbit selected for Mars Observer.

The mission will provide a greatly improved characterization of the atmospheric circulation of Mars and of the factors that govern it; a much more complete description of the present seasonal cycles of water, carbon dioxide, dust, and the key parameters controlling them; important clues and constraints on the nature of past climate change; and the evolution of the Martian atmosphere (Figure 5). The synoptic coverage of atmospheric temperature will make it possible to assess the relative importance of the various circulation mechanisms in transporting heat and momentum as well as in transporting volatiles and dust. By conducting observations over a full set of Martian seasons and at times of varied dust loading and condensation cloud cover, it should be possible to identify feedback mechanisms among circula- 
tion, volatiles, and dust: how each affects the other, and how they collectively affect the climate.

Mars Observer observations will provide a basis for comparing the general circulation of the Martian and terrestrial atmospheres. By using a variety of dynamic models to explore similarities and differences between the two planets, we will gain a more profound perspective on atmospheric dynamics and its underlying controls.

Mars Observer will provide quantitative information on almost all major fluxes and reservoirs that control the seasonal cycles of carbon dioxide, water, and dust. For example, data will be acquired to define the amount of atmospheric water gained or lost at different seasons from the principal surface water reservoirs: the seasonal polar caps, the perennial polar caps, and the mid- to low-latitude regolith. By measuring the amount of atmospheric water present, both as vapor and as ice clouds, and by concurrently obtaining data on atmospheric motions, Mars Observer will permit an evaluation of how far atmospheric water travels from its source regions. Thus the relative roles played in the seasonal water cycle by the polar caps, the regolith, and atmospheric transport will be quantitatively assessed.

Mars Observer will also provide valuable insights into the factors controlling the cycle of global dust storms. By providing global temporal and spatial coverage of the growth phase of global dust storms, by observing the atmospheric circulation, and by concurrently measuring the spatial distribution of atmospheric dust and temperature, a firm basis will be provided for understanding the processes that permit local dust storms to grow rapidly to global proportions and to then decay. Of special interest will be determination of the dust heating/wind speed relationships and understanding the influence of dust loading over the life span of a global dust storm.

It will also be possible to examine the important interactions of the various seasonal cycles. For example, the amount of dust deposited on the seasonal and perennial polar ice deposits is probably critical to the stability of these deposits. The perennial water ice cap in the north and the perennial carbon dioxide ice cap in the south may be due to differing amounts of dust deposited in the two caps, thereby strongly influencing cap albedoes and thus their energy balances. By observing the amount of dust present in the polar atmospheres over the course of a Martian year and by measuring the energy balance of the polar regions, Mars Observer will provide an understanding of the coupling of the dust and carbon dioxide cycles.

An improved understanding of atmospheric circulation and seasonal cycles may eventually provide insight into how astronomical variations of orbital and axial properties have modulated climate. Such astronomical variations on Earth are thought to be a root cause of glacial-interglacial climate variations. This goal will be significantly enhanced if an extended Mars Observer mission or another future mission provides observations over several Martian years. We need to characterize the interannual variation in atmospheric circulation and the volatile and dust cycles to understand their causes. It is necessary to understand the present atmosphere in order to have confidence that we can estimate parameters such as surface pressure under different obliquity conditions.

Observations of the polar layered terrain will advance our knowledge of the nature of the quasi-periodic climate changes on Mars. Estimates of the dust-water ice ratio, topography, and volume in these layers will provide constraints on their formation and the nature of the episodic atmospheric transport of water, carbon dioxide, and fine dust into the polar regions. Determination of the amount and size of dust and volatile particles in the present polar atmosphere will provide an estimate of the present rate of deposition.

The occurrence, abundance, and spatial distribution of hydrous and carbonate minerals in the Martian soil is important to understanding when and how water and carbon dioxide have been lost from the atmosphere by weathering processes. This knowledge will provide constraints on the possible occurrence of warmer, wetter climates in Martian history and on the amount of water that was outgassed into the atmosphere.

Existing data suggest that life does not exist on Mars today, but evidence does suggest that the early Martian climate was quite different from that today and may have been more conducive to life. One interpretation of the dendritic valley systems found in the crater uplands is that liquid water once flowed on the Martian surface. From this we can infer that Martian surface temperatures were considerably warmer and atmosphere pressures much higher than they are today. Life could have developed on Mars during this early climate epoch. If so, some investigators hope that evidence of life might eventually be found within the large areas of the Martian surface that date back to this early, more hospitable period.

The daily and seasonal weather cycles on Mars and Earth have many similarities, but the thin Martian atmosphere, the rapid heating and cooling of the surface, the abundance and distribution of water, the lack of oceans, the annual condensation cycle of carbon dioxide, and the massive dust storms are critical differences. Because both planets show evidence of drastic climate changes in the past, common mechanisms might be responsible (solar luminosity changes, orbital variations, volcanic eruptions, asteroid impacts, etc). The improved understanding of climate change, with consequent effects on biota and biologic processes, will be the most important contribution of Mars Observer to exobiologic science.

\section{Mission Description}

The Mars Observer spacecraft will be launched during the Mars opportunity of September-October 1992. A overview for the 3.4-year Mars Observer mission is shown in Figure 1. The spacecraft will be placed into a low-Earth orbit via a Titan III launch vehicle built by the Martin-Marietta Corporation, Denver, Colorado. Trans-Mars injection will be provided by the transfer orbit stage (TOS) upper stage managed by the Orbital Sciences Corporation, Fairfax, Virginia, and built by the Martin-Marietta Corporation.

Figure 6 shows the Mars Observer spacecraft system configurations for launch and cruise. The spacecraft will maintain a slow, controlled roll in a partially deployed state during its 11-month flight to Mars while carrying out minimum and checkout operations. When it arrives at Mars in August 1993 the spacecraft will be inserted into an initial elliptical orbit with periapsis near the north pole $\left(92.9^{\circ}\right.$ inclination) and an orbital period of 3 sols. The orbit is then 
a) Launch

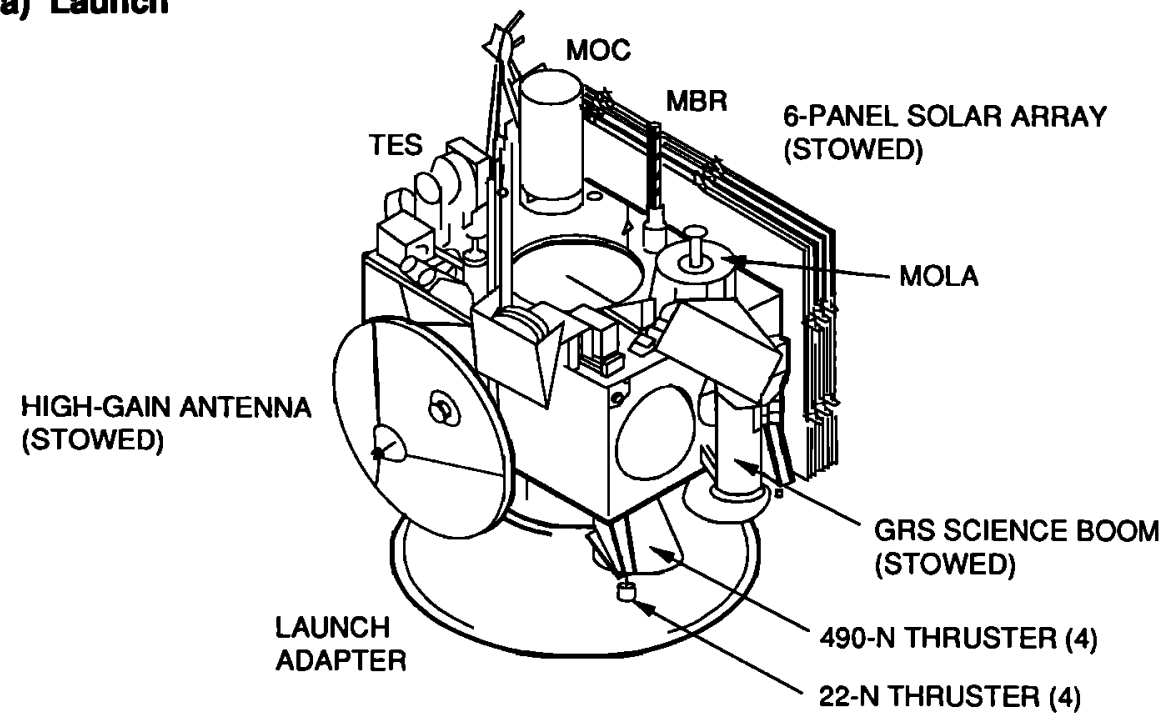

b) Crulse

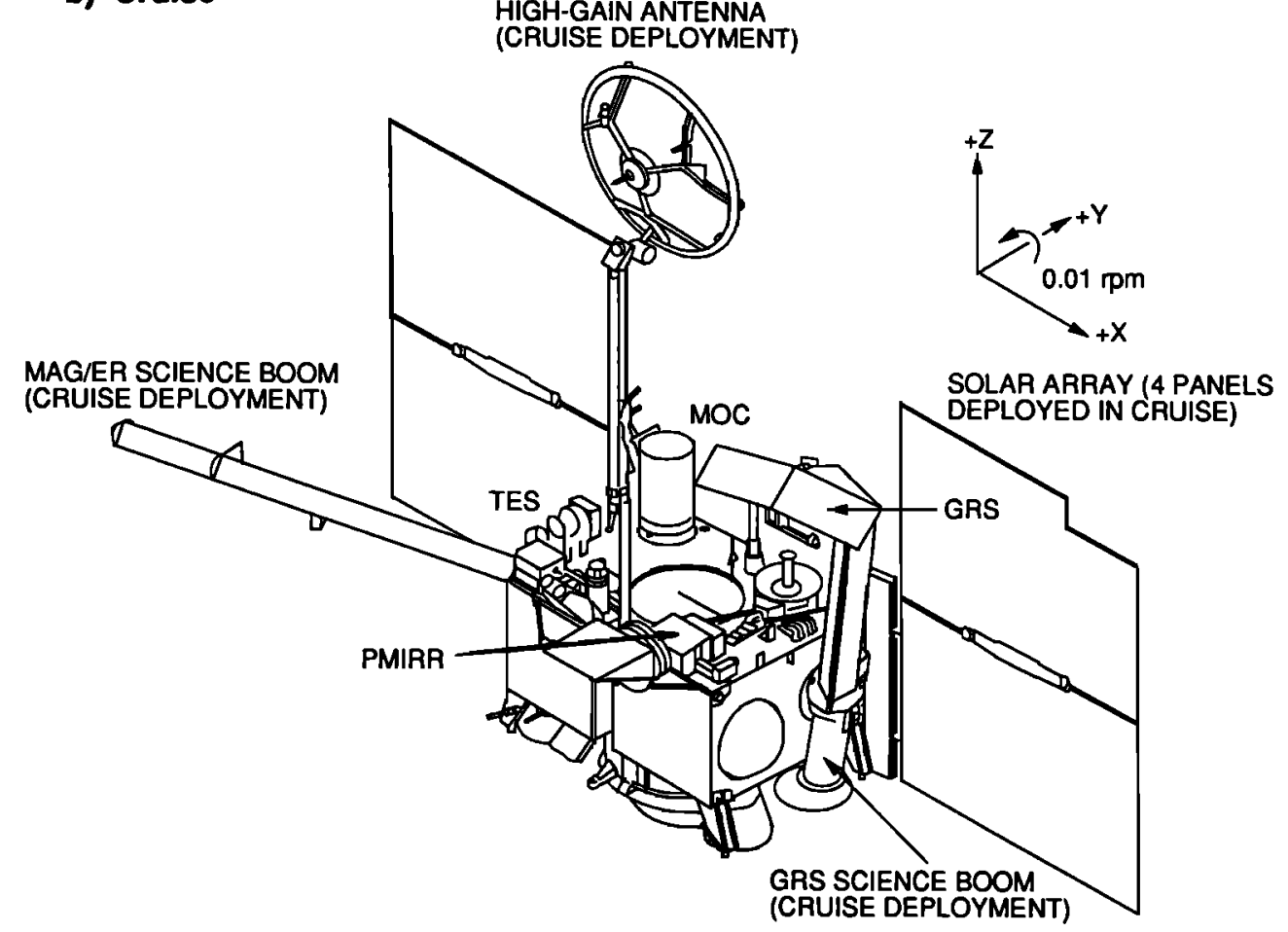

Fig. 6. Configuration of the Mars Observer spacecraft system during launch and parttally deployed during cruise. See Table 1 for instrument names.

adjusted through a series of maneuvers over a 4-month transition period to a near-circular, Sun-synchronous $(0200 /$ $1400 \mathrm{LT}$ ), low-altitude, near-polar orbit. The nominal index altitude is $378 \mathrm{~km}$, but owing to the nonuniformity of the gravity field and the oblateness of Mars the altitude varies from $376 \mathrm{~km}$ near the south pole to $430 \mathrm{~km}$ near the north pole. Once in mapping orbit, final deployment of all booms will be completed (Figure 7), and a spacecraft and instrument checkout will be completed prior to the start of the mapping. The period of systematic mapping observations will extend over a Martian year (687 Earth days) from
December 1993 to November 1995. From September 1995 to February 1996, Mars Observer will support the Russian Mars ' 94 mission, using the Balloon Relay Experiment to relay data collected by scientific packages deployed onto the surface by the Mars ' 94 spacecraft. Simultaneously, Mars Observer will continue its systematic mapping observations.

Figure 8 summarizes the mapping time line relative to Martian seasons and the likely dust storm period. The 4-month orbit transition period is shown ending just before solar conjunction and the beginning of the dust storm period. It is scientifically important to make observations, prefera- 


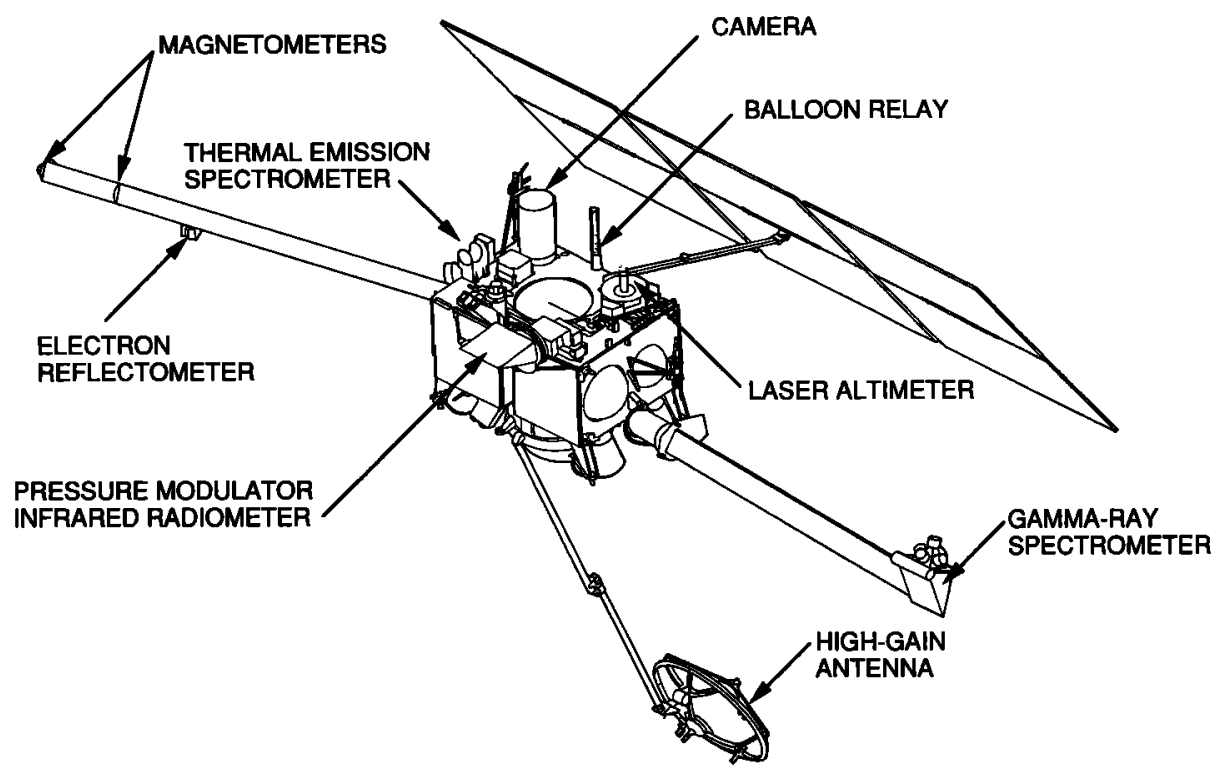

Fig. 7. Configuration of the Mars Observer spacecraft in its fully deployed state during on-orbit mapping. Most of the instruments are located on the nadir (Mars-facing) side of the spacecraft.

bly for an entire global mapping cycle ( 26 sols), before the onset of a major dust storm. Therefore any fuel margin at launch will be used for maneuvers which can shorten the orbit transition period, thereby allowing an earlier start to mapping and acquisition of science data.

The normal sequence of collecting scientific data will be to record continuously for 24 hours and then to play the data back in one daily 10-hour link to a NASA Deep Space Network (DSN) tracking station, while continuing to record data on one of the other tape recorders. Figure 8 also shows that the playback data rate for a 10 -hour DSN pass of five downlinks varies by a factor of 4 with Earth-Mars distance during the mission. The continuous record rate to the tape recorders is about one fifth the playback rate for a 10 -hour link, which also varies by a factor of 4 during the mission. About every third day an additional tracking pass will be scheduled to return high-rate, real-time data.

The mapping orbit will have a repeating ground track that

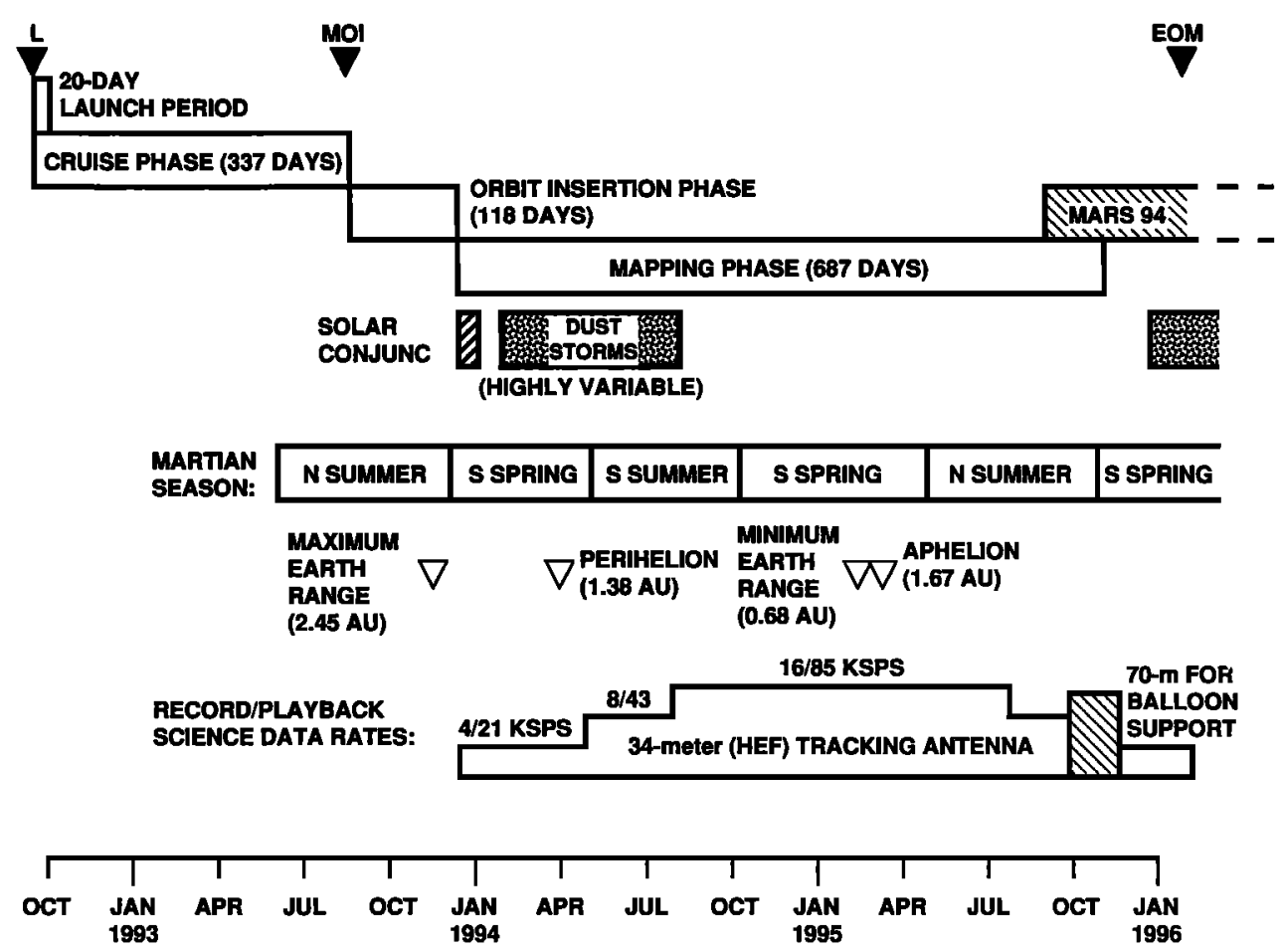

Fig. 8. Mission time line. The variation of data playback rate with Earth-Mars distance is shown along with the Martian seasons. 
allows global coverage to be built up from repeated observational swaths. The orbit has a 118-min period with a 7 -sol near-repeat cycle, offset at the end of 7 sols by $58.6 \mathrm{~km}$. As a result, the planet is repeatedly mapped in 26-sol cycles. Orbit trim adjustments make it possible to obtain coverage over 6917 orbits in 550 sols with a resulting uniform spacing of ground tracks at the equator of $3.1 \mathrm{~km}$, if there were no errors. A "frozen orbit," initialized with a small eccentricity, is used to maintain the orbit shape while minimizing the need for frequent orbit trim maneuvers.

\section{Spacecraft Description and Configuration}

The Mars Observer spacecraft provides a stabilized, nadir-oriented platform for continuous observations of Mars by the science instruments. The spacecraft is being built by the General Electric Astro-Space Division, Hightstown, New Jersey, making maximum use of existing designs and technologies from the Defense Mapping Agency Satellite Program (DMSP) and TIROS weather satellites and the Satcom-K communication satellites. Figures 6 and 7 show the spacecraft and payload at launch, during cruise, and in its fully deployed configuration in Mars orbit. The dimensions of the rectangular bus are $2.1 \times 1.5 \times 1.1 \mathrm{~m}$ in the $X-Y-Z$ dimensions. When fully deployed, the six-panel solar array is $7.0 \times 3.7 \mathrm{~m}$ and develops over a kilowatt of power at Mars. The mass of the spacecraft is about $1028 \mathrm{~kg}$; this includes the 166-kg payload but excludes the $1346 \mathrm{~kg}$ of required propellant, most of which is used for orbit insertion and orbit circularization at Mars. The propellant also includes $63 \mathrm{~kg}$ of hydrazine, which is used for spacecraft control during mapping.

At launch the solar panels and high-gain antenna are folded against the rectangular bus, and the two science booms are in their retracted position. During early cruise the partially deployed spacecraft will be stabilized in a controlled 0.01-rpm roll about the $Y$ axis, and communications with Earth will be via the low-gain antenna. For trajectory correction and orbit insertion maneuvers the spacecraft will orient itself under three-axis control and then return to the cruise attitude. The 6-m science booms cannot be fully extended until mapping. In the mapping orbit the spacecraft will be controlled in three axes, using the horizon sensors to point the science instruments on the $+Z$ face to the nadir. The six-panel solar array will be fully deployed on a boom to track the Sun around each orbit, and the high-gain antenna boom will be fully deployed to track the Earth around each orbit.

\section{Command and Data Handling}

The command and data handling system is built around two redundant flight computers that run in parallel. The flight software includes attitude and articulation control, command processing, some telemetry functions, power and battery management, thermal monitoring and heater control, fault protection, and payload data handling. It also controls science and engineering data streams in record and real-time modes and at various rates and allocations. Each of the four tape drive units has a capacity of 691.2 megabits and can record up to 12 hours of data at the record rate of $16 \mathrm{ksps}$ or up to 48 hours of data at the lowest rate of 4 kilosymbols per second (ksps). Table 1 shows the allocations for the primary record-only data modes used during the mapping phase of the mission. Additional modes are for engineering checkout and to provide real-time transmission to augment the data return from the Mars Observer camera and the thermal emission spectrometer.

Data from the instruments and engineering data from the spacecraft are collected in discrete packets in a regular collection schedule unique to each data mode. The science packet from each instrument includes identification and timing information in addition to the raw science data. The data system collects instrument and spacecraft engineering packets, formats the data into transfer frame packets, and Reed-Solomon encodes the transfer frames before storage on the tape recorders. The spacecraft then applies convolutional encoding prior to transmission via the radio system.

\section{Attitude Control}

Spacecraft pointing control is provided by four reaction wheels. Attitude information is provided by a Mars horizon sensor that defines the nadir direction, a star mapper for inertial attitude, gyros and accelerometers for measuring angular rates and linear accelerations, and multiple Sun sensors. The spacecraft must maintain adequate pointing control and sufficient telemetry to allow reconstruction of the pointing knowledge. The telemetry stream provides data from the sensors sufficient to characterize nadir and highgain antenna pointing to within \pm 3 mrad (per axis, $3 \sigma$ ) and boom-mounted science instrument pointing to within \pm 25 mrad (per axis, $3 \sigma$ ).

\section{Telecommunication}

Spacecraft communication is provided via an $X$ band transponder and command detector system, the high-gain antenna, and three low-gain antennas. The 1.5 -m-diameter high-gain antenna is deployed on a $5.5-\mathrm{m}$ boom to provide clearance over the solar array to point to Earth. The lowgain antennas are used early in cruise and for emergencies. The normal command rate is $125 \mathrm{bit} / \mathrm{s}$, but the spacecraft can also receive commands at data rates in multiples of 2 between 7.8 and 500 bits/s.

\section{Propulsion}

Two independent propulsion systems are provided. All major maneuvers, both in cruise and during orbit insertion, are accomplished by a hypergolic, bipropellant system, which also has substantial redundancy. A hydrazine system is used for orbit trim maneuvers during the mapping period and some attitude control functions, including the unloading of the momentum wheels. The hydrazine thrusters minimize contamination of the instruments during the mapping period.

\section{Power}

Power is supplied by a six-panel solar array mounted on a boom and tracking the Sun around each orbit. When the spacecraft is in eclipse, energy is taken from two nickelcadmium batteries, each with a capacity of $43 \mathrm{amp}$ hours. The orbit-averaged array output will vary from a maximum of about $1400 \mathrm{~W}$ at perihelion (April 1994) to a minimum of about $1150 \mathrm{~W}$ at aphelion (March 1995). On each orbit the spacecraft will be in eclipse from 36 to $41 \mathrm{~min}$, and power will be supplied from the batteries. This power will support 
TABLE 2. Science Investigations and Lead Investigators

\begin{tabular}{|c|c|c|}
\hline Instrument & Lead Investigator & Investigation \\
\hline Gamma ray spectrometer & $\begin{array}{l}\text { W. V. Boynton, University of } \\
\text { Arizona, Tucson }\end{array}$ & $\begin{array}{l}\text { elemental composition of near-surface of Mars; } \\
\text { time and spectra of bursts; neutron } \\
\text { measurements for hydrogen }\end{array}$ \\
\hline Mars Observer camera & $\begin{array}{l}\text { M. Malin, Malin Space Science } \\
\text { Systems, Incorporated, San } \\
\text { Diego, California }\end{array}$ & $\begin{array}{l}\text { global synoptic view, selected moderate and } \\
\text { high-resolution images of the surface }\end{array}$ \\
\hline $\begin{array}{l}\text { Thermal emission } \\
\text { spectrometer }\end{array}$ & $\begin{array}{l}\text { P. R. Christensen, Arizona } \\
\text { State University, Tempe }\end{array}$ & $\begin{array}{l}\text { surface mineralogy; atmospheric dust and } \\
\text { clouds; radiation budget }\end{array}$ \\
\hline $\begin{array}{l}\text { Mars Observer laser } \\
\text { altimeter }\end{array}$ & $\begin{array}{l}\text { D. E. Smith (NASA Goddard } \\
\text { Space Flight Center, } \\
\text { Greenbelt, Maryland }\end{array}$ & $\begin{array}{l}\text { global topography; surface reflectivity at } 1.06 \\
\mu \mathrm{m}\end{array}$ \\
\hline Radio science & $\begin{array}{l}\text { G. L. Tyler, Stanford } \\
\text { University, Stanford, } \\
\text { California }\end{array}$ & $\begin{array}{l}\text { gravitational field; atmospheric refractivity } \\
\text { (temperature and pressure) profiles }\end{array}$ \\
\hline $\begin{array}{l}\text { Magnetometer/electron } \\
\text { reflectometer }\end{array}$ & $\begin{array}{l}\text { M. H. Acuna, NASA Goddard } \\
\text { Space Flight Center, } \\
\text { Greenbelt Maryland }\end{array}$ & $\begin{array}{l}\text { global and local magnetic fields and interaction } \\
\text { with solar wind }\end{array}$ \\
\hline $\begin{array}{l}\text { Pressure modulator } \\
\text { infrared radiometer }\end{array}$ & $\begin{array}{l}\text { D. J. McCleese, Jet Propulsion } \\
\text { Laboratory, California } \\
\text { Institute of Technology, } \\
\text { Pasadena }\end{array}$ & $\begin{array}{l}\text { profiles of temperature, water, and dust; } \\
\text { variation of pressure; monitor polar radiation } \\
\text { balance }\end{array}$ \\
\hline $\begin{array}{l}\text { Mars Balloon Relay } \\
\text { Experiment }\end{array}$ & $\begin{array}{l}\text { J. Blamont, Centre National } \\
\text { d'Etudes Spatiales, Toulouse, } \\
\text { France }\end{array}$ & $\begin{array}{l}\text { relay near-surface images and atmospheric } \\
\text { measurements for the Russian Mars ' } 94 \\
\text { mission }\end{array}$ \\
\hline
\end{tabular}

up to $\mathbf{1 0}$ min of radio transmission in eclipse for the radio science occultation experiment.

\section{SCIENCE PAYloAd}

The scientific instruments for Mars Observer have been designed to meet the scientific objectives of the mission, both by acquiring high-quality data and by maximizing the data that can be returned within the constraints of the mission. As shown in Tables 1 and 2, each instrument will acquire well-defined sets of measurements which will address specific major objectives.
Collectively, the instruments cover much of the electromagnetic spectrum and detect a variety of physical processes; they include complementary high-spectral resolution and broadband measurements, with differing spatial resolution as shown in Figure 9. High-resolution spectroscopy of gamma rays from the Martian surface by the gamma ray spectrometer will provide maps of its elemental composition. Visible and infrared spectral mapping of the sunlight reflected from the Martian surface would provide information about the nature of that surface. The thermal emission spectrometer uses Michelson interferometry in the 6- to

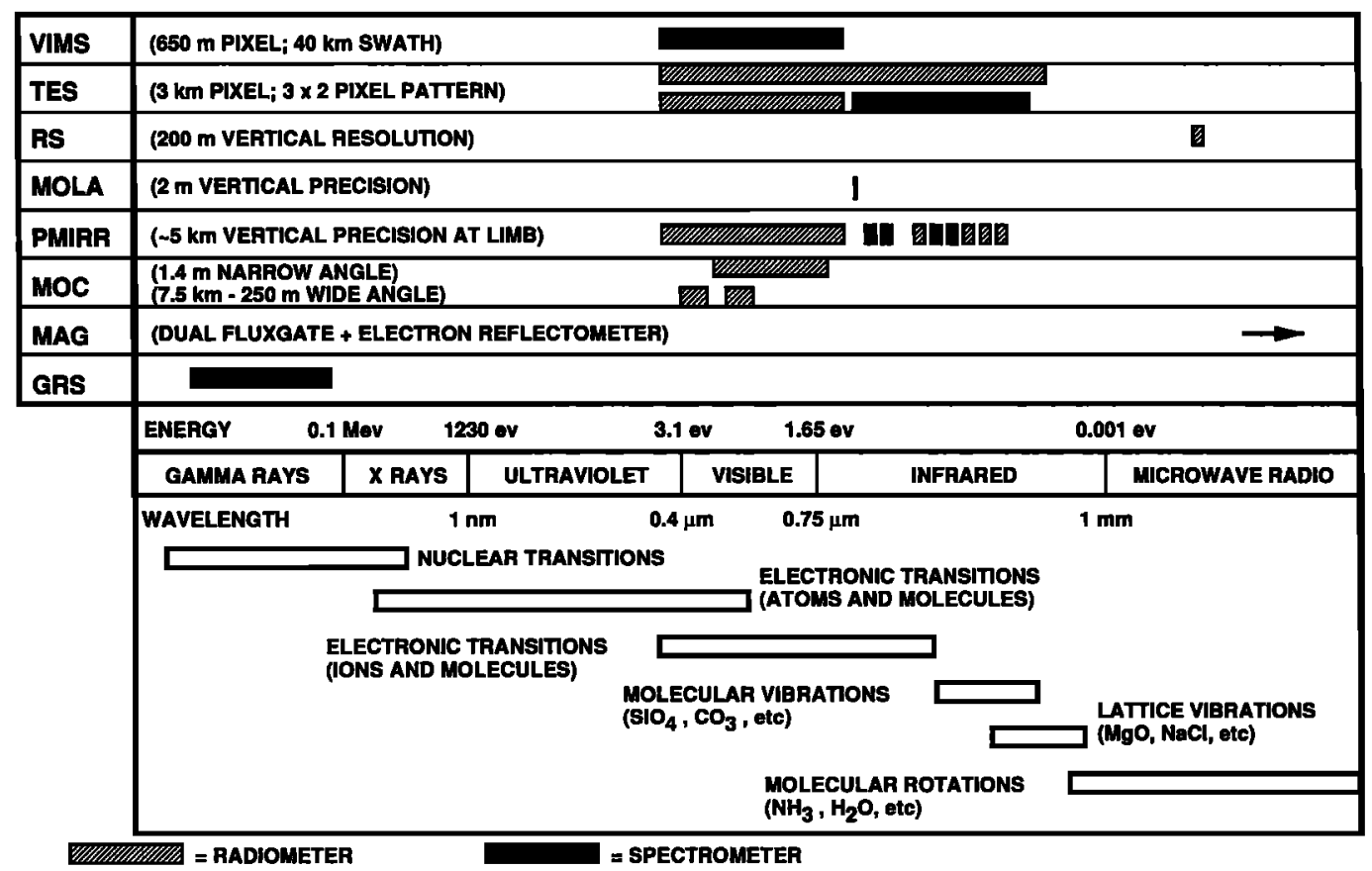

Fig. 9. Spectral coverage and resolution for the Mars Observer instruments relative to various physical processes. VIMS (visible and infrared mapping spectrometer) is included for comparison as discussed in the text. 


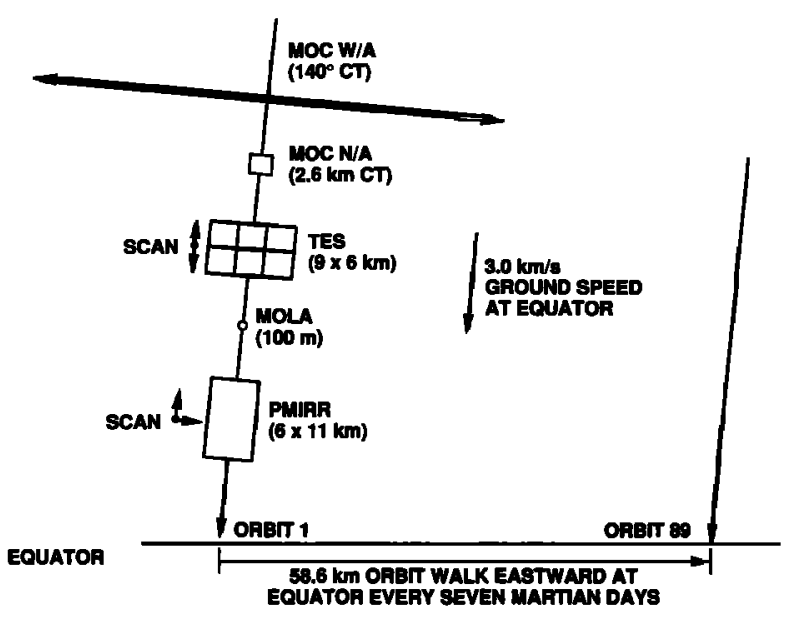

Fig. 10. Relative surface footprints for Mars Observer instruments.

$50-\mu \mathrm{m}$ spectral range to determine and map the composition of minerals, rocks, and ices. Broadband infrared channels are used to map the thermophysical properties of the surface. The visible and near-infrared region was to have been mapped at high spatial and spectral resolution by the visible and infrared mapping spectrometer, whose characteristic are also shown on Figure 9. However, this instrument was removed from the payload for budgetary reasons.

High-resolution and broadband infrared profiles of the Martian atmosphere make it possible for the pressure modulator infrared radiometer to map the three-dimensional and time-varying temperature, water vapor and dust content, and pressure. The other instruments provide a global determination of the topographic, gravitational, and magnetic fields of Mars. Collectively, the instruments will provide a basic global understanding of Mars.

The relative sizes of surface footprints for several instruments are shown in Figure 10. Most instruments are rigidly mounted on the nadir-pointing spacecraft structure and point in the same direction. No movable scan platform is provided; the spacecraft is continuously nadir pointed, rotating at the orbital rate. Those instruments that require scanning or multiple fields of view have internal scanning mechanisms. The gamma ray spectrometer and magnetometer sensor assemblies are mounted on individual booms on the spacecraft (see Figure 7).

The instruments have significantly greater computer capability than those on previous missions. This enables them to run continuously during the course of the mission while accommodating the day-night cycle, a single downlink each day, and the variation in Earth-Mars distance. Most of the instruments provide editing and/or compression of their data prior to downlink. Notable is the thermal emission spectrometer (TES), which utilizes a digital signal processor to do fast Fourier transforms on board the spacecraft, thereby achieving a reduction in data rate from $40 \mathrm{kbit} / \mathrm{s}$ to $4 \mathrm{kbit} / \mathrm{s}$. The Mars Observer camera (MOC) utilizes a 32-bit high-speed microprocessor and a 12-Mbyte buffer to carry out data editing and variable rate compression.

The MOC computational and memory capability will also be utilized by the Mars Balloon Relay Experiment (MBR). The MBR is a French-provided radio experiment that will collect data from transmitters placed on Mars by the Russian
Mars '94 mission. Mars Observer will then forward it to Earth via the DSN. During visibility periods, MBR will transmit a request beacon and receive scientific telemetry from balloons, stations, or rovers on the Martian surface. Doppler measurements on the received carrier will help to locate the stations. The MBR will direct the data stream into the data system of MOC, where it will be stored and transmitted to the Payload Data System (PDS) for downlink to Earth. The Mars Observer orbit is well suited to this relay mode and will make it possible to increase manyfold the data retum from cameras and other instruments on the surface of Mars.

The very strong synergism among the instruments is being exploited in several ways. Six interdisciplinary scientists have been selected to complement the instrument teams (Table 3). In addition, participating scientists, including 10 from the USSR, will be added after launch to further exploit the data returned from the mission. Moreover, as shown in the next section, special attention is being given to provide prompt dissemination of these data sets to the entire scientific community.

\section{Mission Operations ANd Ground System}

\section{Overview}

The Mars Observer mission operations at the Jet Propulsion Laboratory (JPL) will be supported by the NASA Deep Space Network (DSN) and the JPL Space Flight Operations Center (SFOC). Further, science investigation teams will be remotely located at the home institutions of the principal investigators, team leaders, and interdisciplinary scientists. Workstations and NASA electronic communication (NASCOM) links will connect the mission planning and data analysis activities of the scientists and engineers. A simplified diagram of this distributed, end-to-end data and operations system is shown in Figure 11, which emphasizes the various networks and the operating functions in the various locations.

Figure 12 is similar to Figure 11 but emphasizes the data system rather than the operations system. Mars Observer will utilize data standards for packet telemetry and telemetry channel coding and will use a standard formatted data unit for data transfer among ground systems. Mission data will be stored in a central Project Data Base at JPL. Raw science data will consist of a record of each instrument's packet telemetry data provided as an experiment data record; spacecraft position and pointing information data available as a supplementary experiment data record; and related data such as spacecraft status, commands, data availability, and ancillary data. Planning products will include the up-to-date mission sequence plan, schedules and commanding opportunities, and orbit/viewing forecasts. Investigators and analysts will access the Project Data Base to participate in the planning process, to access raw data, and to return reduced data records.

Mars Observer uses existing and planned capabilities of the DSN for acquiring and handling science and engineering telemetry from the spacecraft, as well as radiometric and very long baseline interferometry (VLBI) data to support navigation and radio science objectives. The project will be the first to use nearly all the planned multimission capabilities of the SFOC. These include telemetry processing, flight 
TABLE 3. Interdisciplinary Scientists

\begin{tabular}{|c|c|c|}
\hline Area & Scientist & Objective \\
\hline $\begin{array}{l}\text { Weathering; data } \\
\text { management } \\
\text { and archiving }\end{array}$ & $\begin{array}{l}\text { R. Arvidson, Washington } \\
\text { University, Saint Louis, } \\
\text { Missouri }\end{array}$ & $\begin{array}{l}\text { understanding the mechanisms of weathering, } \\
\text { their temporal variation, and the cycling of } \\
\text { volatiles through the sedimentary system }\end{array}$ \\
\hline Geosciences & $\begin{array}{l}\text { M. Carr, U.S. Geological } \\
\text { Survey, Menlo Park, } \\
\text { California }\end{array}$ & $\begin{array}{l}\text { better understanding of the role of water in } \\
\text { surface evolution, characterization of the } \\
\text { planet's volcanic history, and } \\
\text { determination of the nature and cause of } \\
\text { the uplands/plains dichotomy }\end{array}$ \\
\hline $\begin{array}{l}\text { Polar atmospheric } \\
\text { science }\end{array}$ & $\begin{array}{l}\text { A. Ingersoll, California } \\
\text { Institute of Technology, } \\
\text { Pasadena }\end{array}$ & $\begin{array}{l}\text { definition of atmospheric circulation at all } \\
\text { seasons to specify polarward transport of } \\
\text { carbon dioxide, water, dust, and energy as } \\
\text { well as the radiative and surface fluxes in } \\
\text { the polar regions }\end{array}$ \\
\hline $\begin{array}{l}\text { Surface- } \\
\text { atmospheric } \\
\text { science }\end{array}$ & $\begin{array}{l}\text { B. Jakosky, University of } \\
\text { Colorado, Boulder }\end{array}$ & $\begin{array}{l}\text { determine the nature of the interaction } \\
\text { between the surface and atmosphere to } \\
\text { better understand the processes involved in } \\
\text { the formation and evolution of the Martian } \\
\text { surface and atmosphere }\end{array}$ \\
\hline Climatology & $\begin{array}{l}\text { J. Pollack, NASA Ames } \\
\text { Research Center, } \\
\text { Moffett Field, } \\
\text { California }\end{array}$ & $\begin{array}{l}\text { assess the influence of dust on atmospheric } \\
\text { circulation, the factors which control the } \\
\text { life cycle of dust storms, the role of } \\
\text { dynamics in the seasonal water cycle, the } \\
\text { transport of dust, the constraints on an } \\
\text { early dense carbon dioxide atmosphere, } \\
\text { and the modulation of atmospheric } \\
\text { circulation due to astronomical variations }\end{array}$ \\
\hline $\begin{array}{l}\text { Surface processes } \\
\text { and } \\
\text { geomorphology }\end{array}$ & $\begin{array}{l}\text { L. Soderblom, U.S. } \\
\text { Geological Survey, } \\
\text { Flagstaff, Arizona }\end{array}$ & $\begin{array}{l}\text { separate albedo and slope effects for } \\
\text { reflection and emission measurements for a } \\
\text { wide range of spatial scales and } \\
\text { examination of the pattern of change in } \\
\text { surficial materials from Mariner } 6 \text { and } 7 \\
\text { through Mars Observer }\end{array}$ \\
\hline
\end{tabular}

system commanding, data system operational control, and telecommunications link performance assessment. The telemetry processing will include error detection and correction using the Reed-Solomon encoding information supplied with the data from the spacecraft, depacketization of the transfer frames, placement of the packets into the Project Data Base for access by the investigators, transfer of the engineering data for display at the analysts' workstations, and monitoring of spacecraft engineering data for assessing the health of the spacecraft. The project will provide spacecraft performance analysis, spacecraft navigation, and flight system command sequencing.

\section{Science Operations Planning Computer}

A science operations planning computer (SOPC) will be located at the home institution of each team leader, principal investigator, and interdisciplinary scientist. Each SOPC will be connected to the Project Data Base via 56-kbit/s NASCOM circuits. The SOPCs will enable the instrument teams to exercise substantial direct control of their instruments and will allow interdisciplinary scientists to be directly involved in mission operations. Each SOPC will be provided with command sequence software that will enable the investigators to prepare nearly all of the commands required by their instruments to conduct the desired experiments and to forward those commands directly to the command request file in the project data base.

For planning purposes, the SOPCs will have the capability to display a digital map of Mars with various data set overlays. A global set of mosaicked digital image models (MDIMs) have been constructed from selected Viking im- ages by the U.S. Geological Survey at Flagstaff, Arizona. A sinusoidal equal-area projection is used as a base, since it can be readily manipulated without the assistance of technological experts. In this projection each parallel of latitude is an image line with its length scaled by the cosine of its latitude. Examples of images from MDIMs are shown in Figures 2 and 4 . Each pixel represent $1 / 256^{\circ}$, (about $230 \mathrm{~m}$ ) and lower-resolution versions can be readily produced by factors of 2. Such a base allows efficient computer storage and management, user access, coregistration of data bases, rapid manipulation of data bases for effective analysis and interpretation, and inexpensive preparation of image maps on any desired projections. The sinusoidal equal-area projection will also be used as a baseline for many of the map-oriented products to be generated from Mars Observer data.

\section{SPICE System}

Mars Observer will be the first mission to fully utilize the SPICE concept [Acton, 1991] as a means of producing and accessing ancillary information needed to process raw science data. SPICE is an acronym used to describe five basic kernels of data needed to provide critical information for processing science data files: $S$, spacecraft ephemeris, spacecraft location as a function of time; $P$, planetary ephemerides and selected physical and cartographic constants; I, instrument descriptions, including identification codes used in $\mathrm{E}$ kernels and alignment offset angles used in $\mathrm{C}$ kernels; $\mathrm{C}$, inertial orientation of the spacecraft primary coordinate system in right ascension, declination, and twist angles; and rate changes for the coordinate system; E, event 


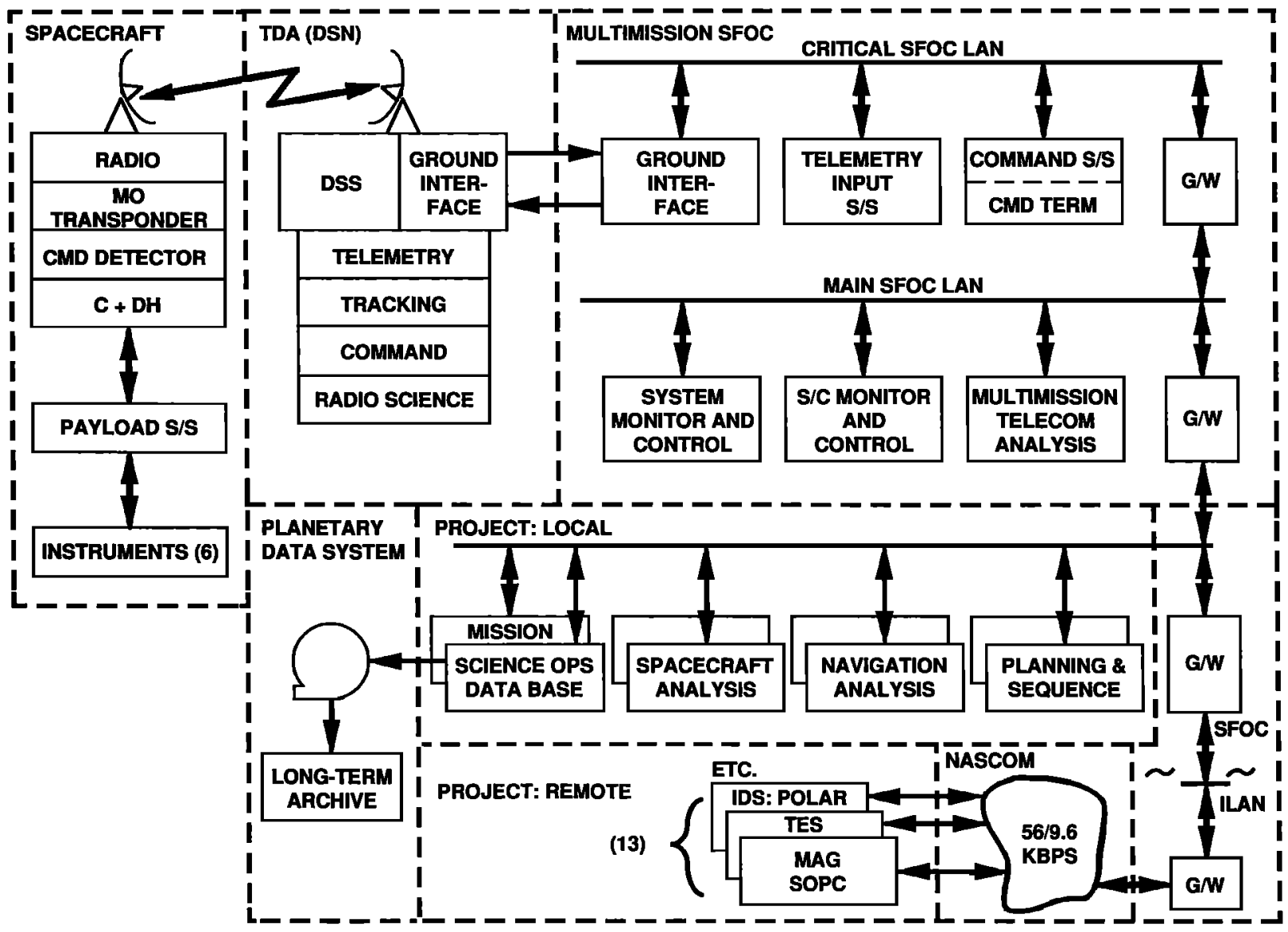

Fig. 11. Ground data system schematic emphasizing the operational functions and the various networks (LAN, Local Area Network; ILAN, Institutional Local Area Network; NASCOM, NASA Communications; etc.) that are connected through gateway $(\mathrm{G} / \mathrm{W})$ computers.

information, including nominal sequences, real-time commands, unscheduled events, and experimenter's notebook comments.

The kernels will be used together with a tool kit of software modules to calculate the basic information required by the investigators in analysis of the experiment data records. SPICE kernels will be generated by various mission operations teams on the basis of orbital tracking, together with instrument information and sequence data obtained from instrument teams. There will be both "actual" and "predict" SPICE files. Predict SPICE kernels will be generated in advance as part of a 28-day sequence planning cycle. This capability will be especially useful for predicting when instrument fields of view will have an opportunity to observe a feature of interest. The actual SPICE kernels will be generated within several weeks after data acquisition for use during the science analysis by each of the experiment teams. The SPICE data set and the associated software tool kit will be released for use with the archived science data.

\section{Commanding-Uplink Process}

The primary command processing consists of generating on 26-sol cycles a stored sequence command load that will be used primarily to control spacecraft bus operations and to update onboard spacecraft ephemerides and star catalogs. This load is generated by an adaptation process consisting of modifying skeleton sequences built and tested prior to launch. Since most instrument operation is nearly independent of spacecraft operations, each principal investigator or team leader may request transmission of noninteractive real-time commands to their instrument at any time. Using the skeleton sequence for each 26-sol cycle, the science investigators develop their observation plans, produce a set of files using sequence software provided with their SOPC, and transmit them to the Project Data Base as sequence requests via the SOPC. Most of these requests are updates to tables in the memory of the individual instrument. Interactive real-time commands are by definition those that affect another instrument or spacecraft subsystem. They are tagged as such and subjected to validation in the command process. The use of such commands is not expected to be common. Mission operations personnel at JPL complete the command process by integrating the independently developed sequence requests, verifying that no spacecraft or mission constraints are violated, and translating the sequence into a command file for uplink to the spacecraft by the DSN.

\section{Data Return-Downlink Process}

The Mars Observer downlink process consists of a daily playback of the spacecraft digital tape recorders plus a real-time data return about every third day. The science data 


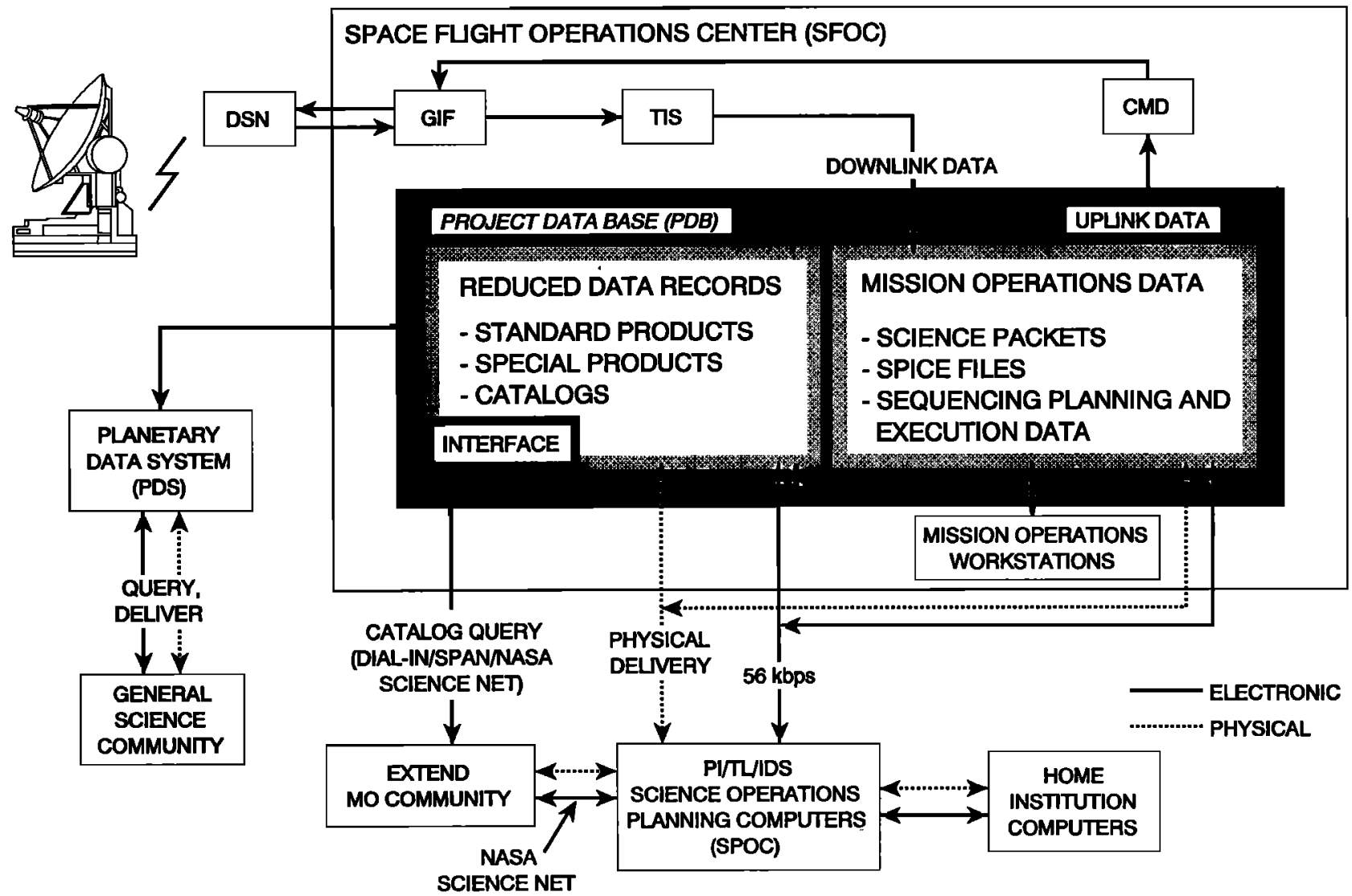

Fig. 12. Ground data system schematic emphasizing the flow of science data through the system.

is placed in the Project Data Base in packets as formatted by the instrument. Averaged over the mission, the raw data rate is more than $120 \mathrm{Mbyte} / \mathrm{day}$. The SOPCs will provide the instrument teams with access to the science telemetry packets within 24 hours of their receipt by the DSN and the SFOC. They are responsible for generating "quick look" science data and/or examining housekeeping data to monitor instrument performance on the basis of data in the experiment data packet.

\section{Science Data Management and Archiving}

Any one instrument on Mars Observer will produce a great deal of data that will significantly augment our understanding of Mars. Cross-instrument analyses utilizing science working groups and other collaborative efforts will allow questions to be addressed that are difficult or impossible to answer with information from a single instrument. Because of the importance of cross-instrument tasks in meeting the Mars Observer science objectives, the probable widespread public interest in new results from Mars, and the strong commitment of the Mars Observer Project Science Group to having documented and reduced data available on a timely basis for the planetary science community, clear data rights and release policies have been established by the Project Science Group.

\section{Data Use Policy}

The data rights policy lays out broad guidelines on the use and release of data to ensure that the science done with Mars
Observer data is maximized and that the expertise of Mars Observer scientists is utilized in the best possible ways. Team leaders and principal investigators will have primary responsibility for the acquisition, reduction, analysis, and production of archival data sets for the data obtained from their instruments. They will also be responsible for publishing scientific results and for timely deposition of reduced data and documentation with the project. Interdisciplinary scientists will chair science working groups, promoting cross-instrument and cross-discipline analyses and helping to develop plans to accomplish the work, participating in the analyses, and summarizing results. However, all Mars Observer scientists are encouraged to participate actively in collaborative efforts. During this initial proprietary period the authorship of collaborative publications shall generally include the participants in the reduction and analysis of data as well as the team leaders and principal investigators.

Data reduction and analysis will take place at investigator facilities, but, as noted, the project will maintain a centralized Project Data Base containing raw data together with reduced data and ancillary information produced at investigator facilities. Two broad categories of reduced data are (1) standard data products that are predetermined and systematically produced, primarily by instrument teams (2) and special data products that will typically be produced by further analysis of one or more standard data products. All standard data products will be returned to the Project Data Base for access by other Mars Observer scientists and for eventual transfer to the Planetary Data System archive. 


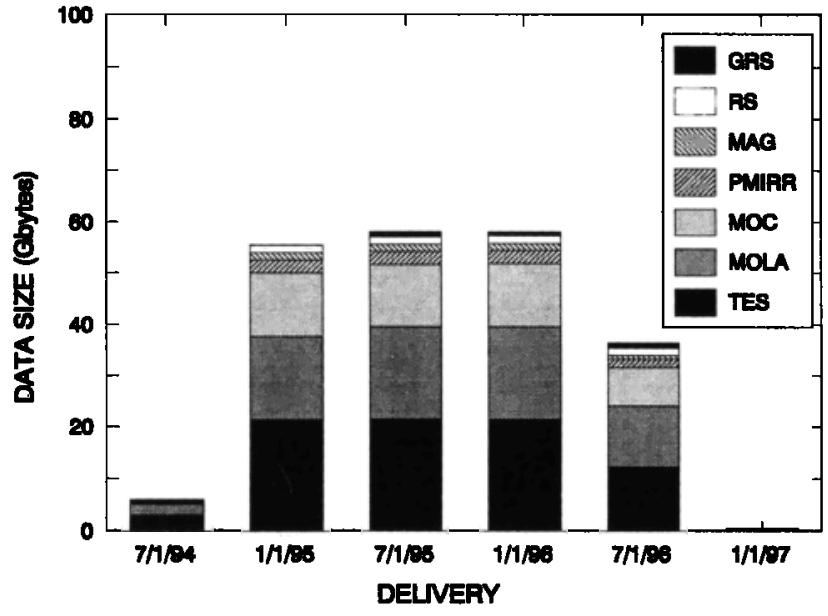

Fig. 13. Standard data product release. Each delivery represents data released to the Planetary Data System on a semiannual basis. Thus the first scheduled delivery would be 6 months after the start of the mapping mission. The image data appear relatively small due to storage in compressed form.

Special data products of widespread interest will also be deposited in the Project Data Base.

\section{Data Release and Archiving}

A cornerstone of the Mars Observer data release policy is that the rate of deposition of reduced data in the Project Data Base shall depend only on the amount of time required to accumulate sufficient data and information to generate the products, to conduct the work needed to generate the products, and to check the results. The default period for proprietary data access and use spans a nominal 6-month period from the receipt of raw data at the home institution responsible for generating the relevant standard data product. During this period the instrument teams are expected to produce standard data products, to validate the products, and to complete and submit for publication their preliminary analysis. Standard data products and documentation will be deposited in the Project Data Base by the end of the 6-month proprietary period, except for certain products that may require longer than 6 months to complete. Subsequently, standard data products, along with the raw packetized data (Mars Observer's version of experiment data records) from which they were generated, and documentation that can be used to reconstruct the processing history, will be transferred from the Project Data Base to the Planetary Data System at systematic intervals (6 months) to make them available to the planetary science community. Figure 13 is a summary of the number and volume of data products to be released to the Planetary Data System as a function of time. The amount of image data appears small relative to other instruments because it is planned to store the images in compressed form.

\section{SUMMARY}

The Mars Observer mission will extend the exploration and characterization of Mars by providing new and systematic measurements of the surface and atmosphere of the planet. These measurements will be made from a lowaltitude polar orbiter over a period of 1 Martian year, permitting repetitive observations of the surface and of the seasonal variations of the atmosphere. The mission is being designed and will be conducted in a manner that will provide new and valuable scientific data at a significant reduction in cost and operational complexity. The data use and release policies ensure expeditions transfer of products to the planetary science community, using the Planetary Data System as the primary long-term archive and distribution system.

Acknowledgments. The research described here was carried out by the Mars Observer Project at the Jet Propulsion Laboratory, California Institute of Technology, under contract with the National Aeronautics and Space Administration. R.E.A. was supported by JPL contract 957584 to Washington University. The authors acknowledge the contribution of the entire project staff. The science objectives for the individual investigations are summarized from the science plans prepared by the lead investigators.

\section{REFERENCES}

Acton, C. H., Jr., The SPICE concept: An approach to providing geometric and other ancillary information needed for interpretation of data returned from space science instruments, in Proceedings of the 2nd International Symposium on Space Information Systems, pp. 1029-1035, American Institute of Aeronautics and Astronautics, New York, 1991.

Albee, A. L., and F. D. Palluconi, Mars Observer: The next Mars mission, J. Spacecr. Rackets, 28, 498-500, 1991.

Beerer, J. G., and R. B. Roncoli, Mars Observer trajectory and orbit design, J. Spacecr. Rockets, 28, 515-521, 1991.

Blume, W. H., S. R. Dodd, and C. W. Whetsel, Mars Observer mission plan, J. Spacecr. Rockets, 28, 522-529, 1991.

Erickson, K. D., and E. L. McKinley, Mars Observer mission operations, J. Spacecr. Rockets, 28, 542-551, 1991.

Esposito, P., D. Roth, and S. Demcak, Mars Observer orbit determination analysis, J. Spacecr. Rockets, 28, 530-535, 1991.

Halsell, C. A., and W. E. Bollman, Mars Observer trajectory and orbit control, J. Spacecr. Rockets, 28, 536-541, 1991.

Komro, F. O., and F. N. Hujber, Mars Observer instrument complement, J. Spacecr. Rockets, 28, 501-506, 1991.

Malin, M. C., G. E. Danielson, M. A. Ravine, and T. A. Soulanille, Design and development of the Mars Observer camera, Int. J. Imaging Syst. Tech., 3, 76-91, 1991.

McCleese, D. J., et al., Remote sensing of the atmosphere of Mars using infrared pressure modulation and filter radiometry, Appl. Optics, 25, 4232-4245, 1986.

McKinley, E. L., Mars Observer project: An introduction, $J$. Spacecr. Rockets, 28, 489-490, 1991.

Palocz, S., Mars Observer mission and systems overview, $J$. Spacecr. Rockets, 28, 491-497, 1991.

Potts, D. L., Mars Observer spacecraft description, J. Spacecr. Rockets, 28, 507-514, 1991

Solar System Exploration Committee, Planetary exploration through year 2000-A core program, NASA Adv. Counc., NASA, Washington, D. C., 1983.

A. L. Albee, Mail Stop 170-25, Division of Geology and Planetary Science, California Institute of Technology, Pasadena, CA 91125.

R. E. Arvidson, Department of Earth and Planetary Sciences, Washington University, Saint Louis, MO 63130.

F. D. Palluconi, Jet Propulsion Laboratory, 4800 Oak Grove Drive, Mail Station 183-501, Pasadena, CA 91109.

(Received May 6, 1991; revised February 11, 1992; accepted February 12, 1992.) 